OPEN ACCESS

Edited by:

Denise Reed,

The University of New Orleans,

United States

Reviewed by:

Julian David Orford,

Queen's University Belfast,

United Kingdom

Hans Middelkoop,

Utrecht University, Netherlands

*Correspondence:

R. P. Hale

rphale@odu.edu

Specialty section:

This article was submitted to Quaternary Science, Geomorphology and Paleoenvironment, a section of the journal

Frontiers in Earth Science

Received: 27 November 2018

Accepted: 31 July 2019

Published: 20 August 2019

Citation:

Hale RP, Wilson CA and Bomer EJ (2019) Seasonal Variability of Forces Controlling Sedimentation

in the Sundarbans National Forest, Bangladesh. Front. Earth Sci. 7:211. doi: 10.3389/feart.2019.00211

\section{Seasonal Variability of Forces Controlling Sedimentation in the Sundarbans National Forest, Bangladesh}

\author{
R. P. Hale ${ }^{1 *}$, C. A. Wilson ${ }^{2}$ and E. J. Bomer ${ }^{2}$ \\ 'Department of Ocean, Earth and Atmospheric Sciences, Old Dominion University, Norfolk, VA, United States, ${ }^{2}$ Department \\ of Geology and Geophysics, Louisiana State University, Baton Rouge, LA, United States
}

Southwest Bangladesh, located on the Ganges-Brahmaputra-Meghna delta, is experiencing the impacts of sea level rise (SLR) due to processes at both the local and global scale. In particular, regional alterations of the hydrodynamic network, due to embankment construction, have drastically altered effective SLR, placing millions of inhabitants at risk of prolonged inundation, and threatening the world's largest continuous mangrove stand, the Sundarbans National Forest (SNF). In order to effectively employ landscape recovery solutions, an understanding of local sediment transport and deposition is critical. This field-based study investigates the sediment dynamics between the mangrove platform and tidal channels of the SNF using data from a variety of instruments and sediment samples collected within a forested subbasin ( $20 \mathrm{~km}^{2}$ ) fed by a major tidal channel. We observe profound seasonal variability within the sub-basin, with the wet season exhibiting a deeper and longer inundation of the mangrove platform and greater suspended sediment concentrations (SSC). Further, there exists a trend of decreasing SSC and median grain size from the perimeter of the SNF to the interior, and decreasing SSC from the tidal channel to the platform at both locations. We project seasonal platform sedimentation rates ranging from $0.17 \pm 0.16 \mathrm{~cm}$ in the dry season to $1.8 \pm 0.35 \mathrm{~cm}$ in the wet season. Importantly, the annual deposition rate measured at either location is sufficiently rapid to keep pace with observed rates of effective SLR published in other studies $(\sim 1.0-1.7 \mathrm{~cm} /$ year). Based on our results, it appears that many controls on sedimentation are both covariant and of similar importance to land aggradation in the SNF. While inundation depth and frequency will likely increase under future SLR scenarios, sediment supply is threatened by India's proposed River Linking Project, which could decrease the sediment loads of the Ganges and Brahmaputra Rivers by as much as 75 and $25 \%$, respectively. These rivers provide the sediment for the entire delta, and we predict that with decreasing SSC, some regions - particularly interior sediment-depleted regions - may begin to deteriorate and become submerged, including within the SNF.

Keywords: hydrodynamics, Bangladesh, sediment transport, seasonal variability, mangrove forest 


\section{INTRODUCTION}

Mangrove forests provide a variety of societal benefits, including storm-surge buffering (e.g., Badola and Hussain, 2005), economic stimulus from ecotourism (e.g., Satyanarayana et al., 2012), land stability and erosion minimization (e.g., Carlton, 1974; Saenger and Siddiqi, 1993), and carbon sequestration (e.g., Mcleod et al., 2011; Ray et al., 2011; Alongi, 2012; Twilley et al., 2018). As populations around the world move toward coastlines and either alter landscapes or eradicate mangroves altogether, it is imperative that we understand how these systems behave under pseudo-natural conditions to help protect these valuable resources. This study will focus on a portion of the Sundarbans National Forest (SNF), a relatively pristine mangrove forest located in southwestern Bangladesh (Figure 1). The total extent of the Sundarbans reaches across political boundaries into India, expressing a continuum of fluvial and tidal forces with increased distance from the modern Ganges-BrahmaputraMeghna River mouth (Allison and Kepple, 2001; Rogers et al., 2013; Flood et al., 2015, 2018). Immediately to the north of the SNF is an inhabited region where the construction of earthen embankments ("polders") has resulted in a substantial modification of the tidal prism, leading to tidal amplification and extensive network reorganization (e.g., Pethick and Orford, 2013; Wilson et al., 2017). While attributed to anthropogenic modification, this tidal amplification also impacts the SNF, andcoupled with eustatic sea-level change and compaction-has resulted in an effective sea level rise of $0.7 \mathrm{~cm} /$ year at the southern coast, increasing to $1.7 \mathrm{~cm} /$ year near the city of Khulna, which enhances flood risk across the entire tidal deltaplain (Figure 1; Steckler et al., 2010; Pethick and Orford, 2013). Furthermore, the National River Linking Project (NRLP) proposed by India is expected to reduce freshwater discharge of the Ganges River by $24 \%$, with a corresponding reduction in sediment load by $39-$ $75 \%$ if fully implemented (Higgins et al., 2018). Those authors further predict a reduction in delta-wide aggradation from 0.36 to $0.25 \mathrm{~cm} /$ year under this scenario. Given that $>60 \%$ of the sediment deposited in the SNF is recently derived from the mainstem Ganges-Brahmaputra-Meghna (Allison and Kepple, 2001; Rogers et al., 2013), we expect the impacts of this decrease in sediment supply to be particularly acute in the SNF.

Several recent investigations have investigated the health and stability of the SNF platform elevation in the face of locally accelerated relative sea level rise (e.g., Rogers et al., 2013; Auerbach et al., 2015; Bomer et al., in review). These previous efforts have addressed the timing of seasonal sedimentation, and estimated deposition rates of $1.0 \pm 0.9,1.1 \pm 1.0$, and $1.32-2.16 \pm 0.17-0.26 \mathrm{~cm} /$ year, respectively. Collectively, these studies demonstrate that at present, there is sufficient sediment being delivered to the SNF for the vertical accretion to keep pace with rates of local sea level rise, and that the platform is maintaining its elevation relative to mean high water. However, knowledge gaps remain concerning what controls sediment delivery and accumulation within the SNF, and how this varies spatially. To address this need, this study investigates sediment delivery and deposition within a sub-basin in the SNF, and how we might expect similar regions to respond given changes to these functions. Specifically, we combine data from acoustic and optical instrumentation with physical sediment samples to address seasonal changes in: (i) tidal channel suspended sediment concentrations (SSC), water velocity, and grain size; and (ii) platform inundation depth, duration, and grain size. These specific parameters have been identified as especially important in controlling wetland sedimentation in zero-dimensional, massbalance models of marsh growth and mangrove sediment dynamics (e.g., Krone, 1987; Allen, 1990; French, 1993; Furukawa and Wolanski, 1996; Furukawa et al., 1997; Temmerman et al., 2004; Capo et al., 2006; Horstman et al., 2015).

\section{STUDY AREA}

The SNF is the largest continuous mangrove stand in the world, with a total area of $\sim 10,000 \mathrm{~km}^{2}$ comprised of several major tidal channels separated by vegetated sub-basins (Figure 1). This project focuses on a $\sim 20-\mathrm{km}^{2}$ sub-basin in north-central SNF, immediately adjacent to the human-modified agricultural region, $\sim 100 \mathrm{~km}$ inland from the Bay of Bengal (Figure 1). Water and sediment are primarily delivered to this region by a tidal channel extending from the Sutarkhali River, called the Sorbathkhali, which lies between two primary conduit channels that connect this region to the broader Ganges-Brahmaputra-Meghna river system: the Pussur and Shibsa Rivers (Figure 1). The majority of freshwater and sediment are delivered to the region by inland advection from the Bay of Bengal during the southwest monsoon season (July to September; e.g., Barua, 1990; Barua et al., 1994; Allison and Kepple, 2001; Rogers et al., 2013; Shaha and Cho, 2016; Hale et al., 2019). As a result, the entire SNF is characterized by fresh water ( $\sim 0$ PSU) from July to late November, and brackish to saline waters $(\sim 20-30$ PSU) for the remainder of the year (Shaha and Cho, 2016; Ayers et al., 2017). Accompanying the fresh water is a substantial change in local suspended sediment concentration (SSC), which varies by a factor of five or more from dry-season minima $(\sim 0.2 \mathrm{~g} / \mathrm{l})$ in June to Monsoon maxima $(>1.5 \mathrm{~g} / \mathrm{l})$ in September (Hale et al., 2019). These previous studies provide an excellent backdrop for the research presented here, which focuses on the specific processes responsible for delivering sediment from the major tidal channels onto the mangrove forest platform within the SNF.

The specific focus of this study is on two areas within a representative $\sim 20-\mathrm{km}^{2}$ sub-basin in the SNF, supplied with sediment and water by a single channel, the Sorbothkhali (Figure 1). The Sorbathkhali is $\sim 90 \mathrm{~m}$ wide at its diversion from the Sutarkhali River, with typical thalweg depths ranging from 7 to $10 \mathrm{~m}$. The channel narrows and shoals with distance away from this junction, to a width of $\sim 15 \mathrm{~m}$ and depth of $\sim 0 \mathrm{~m}$ at most interior reaches during spring low tides. While the absolute platform elevation is difficult to constrain owing to seasonal variability and limited benchmark availability, the average inundation depth has previously been reported as $\sim 0.3 \mathrm{~m}$ (Auerbach et al., 2015). Assuming that the Sorbathkhali channel is the conduit for the majority of flooding water (Auerbach et al., 2015), approximately $6 \times 10^{6} \mathrm{~m}^{3}$ of water is conveyed during spring tides (e.g., Auerbach et al., 2015; Bomer et al., in review). 

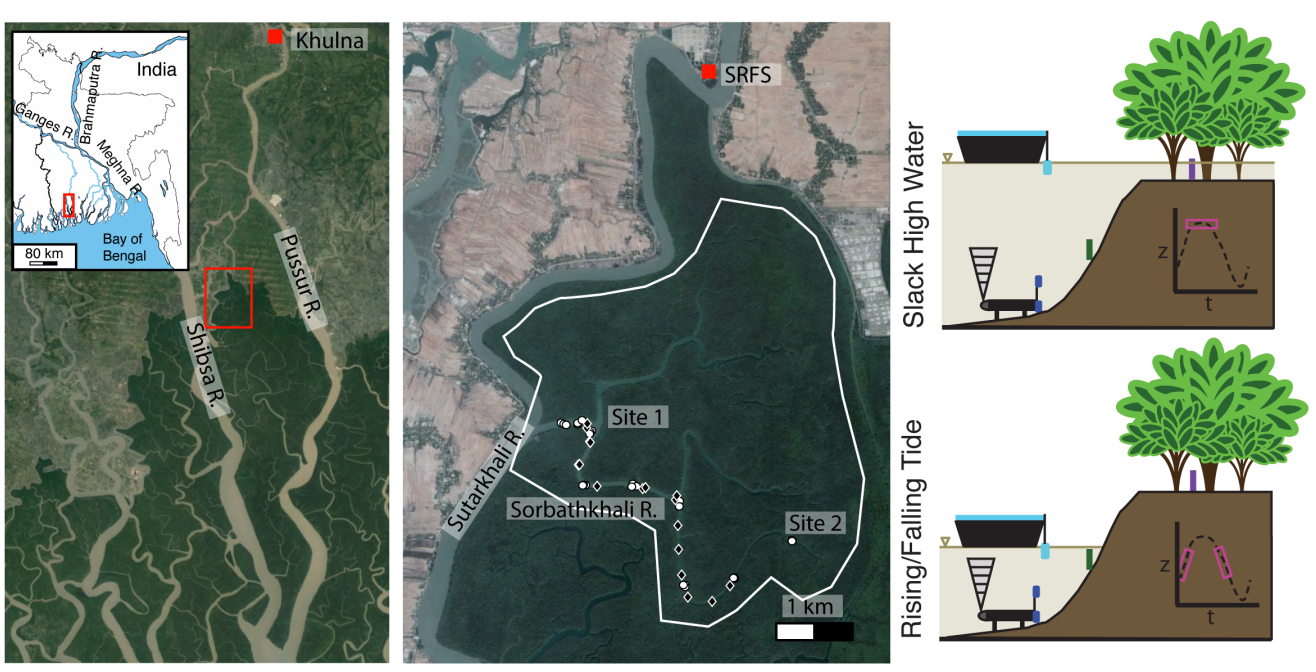

FIGURE 1 | Satellite images of the study area, highlighting the Sundarbans mangrove forest (dark green) and representative sub-basin (red box) located proximal to the heavily modified polder region (light green-tan). Middle image is a zoom of the sub-basin, highlighting the location of the long-term sensors at the Suterkhali Reserve Forestry Station (SRFS), Sites 1 and 2 where single-day measurements were made seasonally, and sediment grab locations for the wet (diamond) and dry (circle) seasons. An approximate boundary for this sub-basin is sketched in white. Right-hand panel depicts the experimental design at Sites 1 and 2, demonstrating the relative locations of the ADCP measurements (gray triangle), channel-bottom measurements (blue), channel-surface measurements (cyan), channel-bank velocities (green), and platform measurements (purple). Satellite imagery via (Google Earth, 2015, 2017).

The primary vegetation here is the endangered mangrove Heritiera fomes, locally known as the Sundri, which can grow to a maximum height of $25 \mathrm{~m}$ and prefers freshwater. Other species found in this region, presented using their local names, include Gewa, Bain, Pussur, and Kakra (Ghosh et al., 2016).

\section{MATERIALS AND METHODS}

This study benefits from the use of a variety of datasets. Longterm seasonal changes were measured using a Schlumberger conductivity, temperature, depth (CTD) sensor continuously deployed in a channel adjacent to the SNF at the Sutarkhali Forest Ranger Station (SFRS) from October 2017 to March 2018 (Figure 1). In addition, suspended sediment concentration was recorded $\sim 30 \mathrm{~cm}$ above bed (cmab) using a Fisher Scientific optical backscatter sensor $3+$ (OBS). The OBS was calibrated to SSC using a method described by Hale et al. (2019). In short, water samples were collected at the same time and depth as OBS readings, prior to the long-term instrument deployment. Known sample volumes were then filtered using $0.4 \mathrm{~mm}$ glass-fiber filters to determine SSC. A linear relationship between measured OBS response and filtered SSC was then derived.

Within the SNF, discrete observations were made during individual spring tide cycles during both the wet and dry seasons at two locations within the sub-basin: an exterior site approximately $1 \mathrm{~km}$ from the confluence with the Sutarkhali River (Site 1; Figure 1), and an interior site approximately $5 \mathrm{~km}$ further into the forest (Site 2; Figure 1). These locations were selected based on their relative proximity to the sediment source (the Sutarkhali River), and correspond to the locations used in a companion study of platform accumulation
(Bomer et al., in review). Wet season measurements were collected in October 2017 and dry season observations took place in March 2018. On each survey day, measurements began as close to low tide as possible, and continued through the entire period of platform inundation. Due to daylight constraints, our results are focused primarily during the rising limb, slack high, and onset of the ebb portions of the tidal cycle, with limited observations at the termination of the falling limb. While the specifics of each survey day varied slightly due to instrumentation and environmental conditions, the general approach included: near-bottom measurements of water depth, velocity profiles $(50-250 \mathrm{cmab})$, temperature, and SSC (5 cmab); water-surface measurements of temperature, conductivity, and SSC, and; measurements of water depth and SSC from the forest platform during periods of inundation (Figure 1). Velocity profiles were measured using an acoustic Doppler current profiler (ADCP), which measured velocity in $10-\mathrm{cm}$ bins extending from 50 to $250 \mathrm{cmab}$. Measurements were collected at $1 \mathrm{~Hz}$ in 512-second bursts every $10 \mathrm{~min}$, with the burst-averaged velocities reported herein. During the dry season, additional water velocity measurements were made further up the bank using a tilt current meter deployed $\sim 1.25 \mathrm{~m}$ below the platform elevation. Platform measurements occurred at distances of $\sim 50 \mathrm{~m}$ and $\sim 90 \mathrm{~m}$ from the creek bank for Sites 1 and 2, respectively, at the locations of the sediment elevation tables used in a concurrent study by Bomer et al. (in review; Figure 1). Efforts were made to ensure that the exact locations of instrument deployment were consistent across seasons. Surface water samples were also collected every 30-60 min to calibrate optical instrumentation measuring SSC, using the method described previously in this section. 
We used the observed reduction in platform SSC to estimate the deposition $(d z)$ associated with individual tidal cycles, according to the following equation:

$$
d z=[(S S C 1-S S C 2) \times h] / \rho_{p}
$$

where SSC1 and SSC2 are the pre-slack-water maximum and post-slack-water minimum SSC $\left(\mathrm{kg} / \mathrm{m}^{3}\right), h$ is the maximum inundation depth $(\mathrm{m})$, and $\rho_{p}$ is the bulk density of the platform $\left(\mathrm{kg} / \mathrm{m}^{3}\right)$. All values used for this calculation are described in Table 1.

In addition to the observations made using acoustic and optical instrumentation, sediment samples were collected from the platform at Sites 1 and 2 , and at locations spaced throughout the sub-basin at approximately 400-m intervals in between sites, with repeat sampling in March 2015 and October 2015 (Figure 1). Platform samples used to measure grain size were composed of the seasonally deposited sediment recovered from the sediment tiles deployed as part of a companion study by Bomer et al. (in review). Channel samples ( $n=40$ ) were collected at or near low tide, and an effort was made to collect sediment from the mid/upper bank, as well as the channel center (presumptive thalweg) at each station. To the best of our ability, we scraped the upper $\sim 1 \mathrm{~cm}$ of these samples to represent the recently transported material. All samples were measured for their particle size distribution using a Malvern Mastersizer 2000 laser diffraction particle size analyzer, after a $\sim 0.5 \mathrm{~g}$ subsample was immersed in sodium hexametaphosphate and sonified to disaggregate particles. For simplicity, the median grain size (D50) is presented in this study. Finally, sediment dry bulk density was calculated as the quotient of dry sediment weight over volume, using sediment from the upper $10 \mathrm{~cm}$ of cores collected at sites 1 and 2 .

\section{RESULTS}

\section{Multi-Year Observations From Channel Adjacent to SNF}

Tidal-channel water depth at Suterkhali Reserve Forestry Station (SRFS) demonstrates a strong semi-diurnal signal, and pronounced spring-neap variability (Figure 2A). Peak water levels were higher in the wet season than the dry by $\sim 25 \mathrm{~cm}$, while the water level minimum during the dryseason observations was $\sim 33 \mathrm{~cm}$ lower than that of the wet season (Figures 2A,D).

Conductivity during our study period began to increase in early November, reaching a maximum of $\sim 6$ PSU in early January, before apparently dropping to $\sim 3$ PSU until recovery in March (Figure 2B). An important caveat here is that the CTD was covered in encrusting worms upon recovery. Conductivity during the dry-season field work, as measured by replacement sensors not subjected to long-term deployment, was closer to 15 PSU (Figure 2B). We suggest that the observed salinity decrease that began in early 2018 is the product of biofouling.

Although the OBS record is incomplete because of deployment challenges in this harsh environment, we can see that SSC at SFRS ranged from 0.05 to $\sim 1.0 \mathrm{~g} / \mathrm{l}$ during the wet season field work, and decreased to a minimum of $0.01-0.15 \mathrm{~g} / \mathrm{l}$

TABLE 1 | Values of water level, SSC, and velocity measured during the single-day observations.

\begin{tabular}{|c|c|c|c|c|c|}
\hline & & Site 1 - Wet & Site 2 - Wet & Site 1 - Dry & Site 2 - Dry \\
\hline \multirow[t]{3}{*}{ Tide data } & Absolute max (m) & 4.881 & 4.885 & 4.667 & 4.532 \\
\hline & Absolute min (m) & 0.741 & 0.594 & 0.191 & 0.343 \\
\hline & Range (m) & 4.14 & 4.291 & 4.476 & 4.189 \\
\hline \multirow[t]{8}{*}{ Platform data } & Inundation time (min) & 266 & 321 & 122 & 105 \\
\hline & Inundation depth (cm) & 38.8 & 42.7 & 6 & 7.5 \\
\hline & Mean SSC (g/l) & 0.27 & 0.22 & 0.08 & 0.05 \\
\hline & Flood-max SSC (g/l) & 0.39 & 0.33 & 0.2 & 0.06 \\
\hline & Ebb-min SSC (g/l) & 0.14 & 0.15 & 0 & 0.03 \\
\hline & Sediment dry bulk density $\left(\mathrm{kg} / \mathrm{m}^{3}\right)$ & 1100 & 670 & 760 & 700 \\
\hline & Predicted seasonal deposition (cm) & 1.6 & 2.1 & 0.3 & 0.06 \\
\hline & $\begin{array}{l}\text { Measured vertical accretion (Bomer } \\
\text { et al., in review) }(\mathrm{cm})\end{array}$ & $1.93 \pm 0.46$ & $0.94 \pm 0.24$ & $1.07 \pm 0.25$ & $0.81 \pm 0.28$ \\
\hline \multirow[t]{2}{*}{ Channel surface } & Mean SSC (g/l) & 0.52 & 0.50 & 0.32 & 0.10 \\
\hline & Max SSC (g/l) & 0.86 & 0.79 & 0.64 & 0.55 \\
\hline \multirow[t]{6}{*}{ Channel bottom } & Mean SSC (g/l) & 0.62 & na & 0.41 & 0.11 \\
\hline & Max SSC (g/l) & 0.90 & na & 0.66 & 0.46 \\
\hline & Flood Umax (m/s) & 0.64 & 0.44 & 0.45 & 0.30 \\
\hline & Ebb Umax (m/s) & 0.24 & 0.25 & 0.30 & 0.69 \\
\hline & $\mathrm{Re}^{*}$ (average) & 0.27 & & 0.48 & \\
\hline & $\theta_{t}$ (average) & 1.25 & & 0.47 & \\
\hline
\end{tabular}

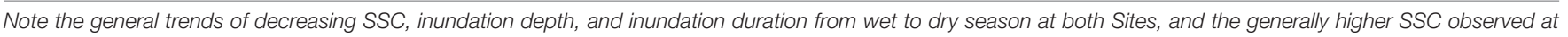
Site 1 vs. Site 2, NA: NA stands for not applicable, as the instrument was not monitoring at that time/location. 


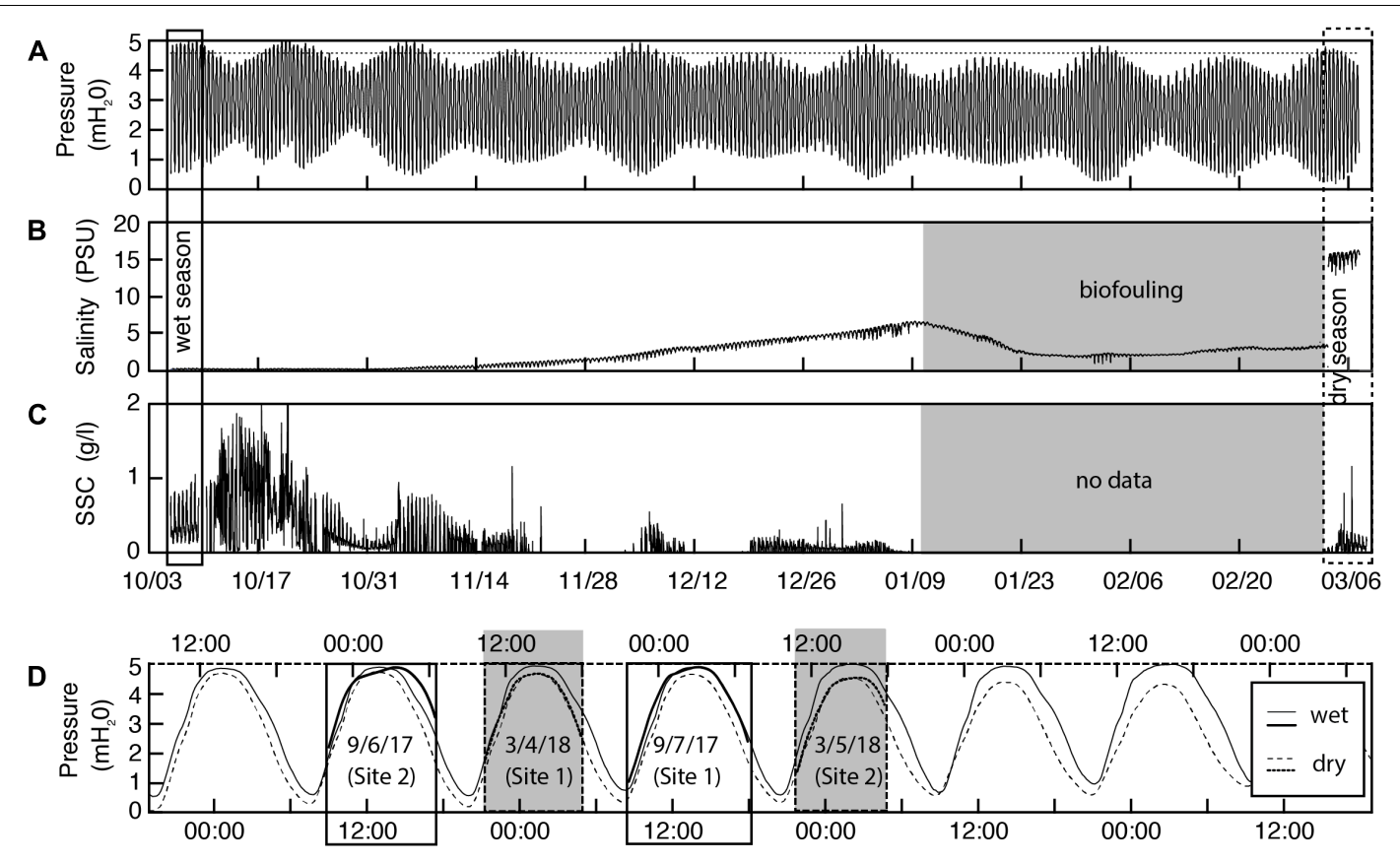

FIGURE 2 | Long-term observations of pressure (A), conductivity (B), and SSC (C) at SRFS, and focused observations of water level during the single-day observation periods at Sites 1 and 2 (D). Wet and dry field seasons are outlined by solid and dashed boxes. Notice the general decrease in water level and SSC, and increase in conductivity during the dry season. The dashed line in panel (A) is the platform elevation at Site 1 for reference. For panel (D), dashed and light solid lines are from SRFS, while dark solid lines are from Sites 1 and 2.

in early January, at which point the sensor appears to have been completely buried before being re-exposed in March. SSC during the dry season field work ranged from 0.01 to $0.3 \mathrm{~g} / \mathrm{l}$ (Figure 2C).

\section{Single-Day Hydrodynamics and Sediment Dynamics Within the SNF}

Tidal range remained relatively constant during the days during which discrete sampling took place (Figures 2A,D). As measured at the SRFS, the tidal range during Site 1 sampling days was 4.14 and $4.48 \mathrm{~m}$ for wet and dry seasons, respectively (Table 1 and Figure 3). Similarly, Site 2 sampling days exhibited tidal ranges of 4.29 and $4.19 \mathrm{~m}$ for the wet and dry seasons, respectively.

Despite the similarity of tidal range, the platform inundation depth and duration were drastically different as a result of the overall drop in absolute water levels during the dry season (Figure 2A). Site 1 was inundated for $266 \mathrm{~min}$ during the wet season survey day, and to a maximum depth of $0.39 \mathrm{~m}$ (Table 1). The same location was inundated for 122 min during the dry season, to a maximum depth of $0.06 \mathrm{~m}$, which correspond to reductions of 54 and 84\%, respectively (Table 1 and Figure 3 columns I, III). At Site 2, the platform was inundated for $321 \mathrm{~min}$, to a maximum depth of $0.43 \mathrm{~m}$ during the wet season. During the dry season, on the other hand, the inundation duration reduced $67 \%$ to $105 \mathrm{~min}$, and inundation depth reduced $81 \%$ to $0.08 \mathrm{~m}$ (Table 1 and Figure 3 columns II, IV). On the platform, average SSC was substantially greater during the wet season than the dry season at both locations. At Site 1, we observed an average SSC of $0.27 \mathrm{~g} / \mathrm{l}$ during the wet season, versus $0.08 \mathrm{~g} / \mathrm{l}$ during the dry season. Site 2 was similarly dramatic, with average SSC dropping from 0.22 to $0.05 \mathrm{~g} / \mathrm{l}$ between seasons (Table 1 and Figure 3).

Water velocities were faster during the wet season than the dry season, although not substantially. At Site 1 within the channel, the maximum depth-averaged flooding velocity was $0.64 \mathrm{~m} / \mathrm{s}$ during the wet season, compared to $0.45 \mathrm{~m} / \mathrm{s}$ during the dry season, a 30\% reduction (Table 1 and Figure 3). Moving further into the sub-basin at Site 2 , the depth-averaged velocity reduced $\sim 47 \%$ from $0.44 \mathrm{~m} / \mathrm{s}$ in the wet season to $0.30 \mathrm{~m} / \mathrm{s}$ in the dry season (Table 1 and Figure 3). One complication with the burstaveraged velocities presented here is that during ebbing tides at Site 1, the interplay between two channels (Figure 1) sets up $\sim 30$-m-wide eddies, resulting in rapid flow reversals on $\sim 1$ minute time scales. Because the burst length is $\sim 8.5 \mathrm{~min}$, the burst-averaged velocity (Figure 3) is considerably lower than the instantaneous velocity. We do not observe this complication during flooding tides at Site 1 , because flow is divergent rather than convergent, preventing eddy formation. At Site 2 , the single channel results in uniformly directed currents, with ebb tide burst-averaged velocities that are faster than at Site 1 (Figure 3).

Average near-bed SSC reduced 33\% from 0.62 to $0.41 \mathrm{~g} / \mathrm{l}$ from wet to dry seasons at Site 1 (Table 1 and Figure 3). Unfortunately, near-bed SSC was not measured at Site 2 in the wet season. During conditions of reduced water velocity observed during the dry season, near-bed SSC was $\sim 0.11 \mathrm{~g} / \mathrm{l}$. SSC at the water surface was substantially greater during the wet season than the dry season at both locations. From the OBS, wet season mean SSC was 0.52 and $0.50 \mathrm{~g} / \mathrm{l}$ at Sites 1 and 2, respectively. During 

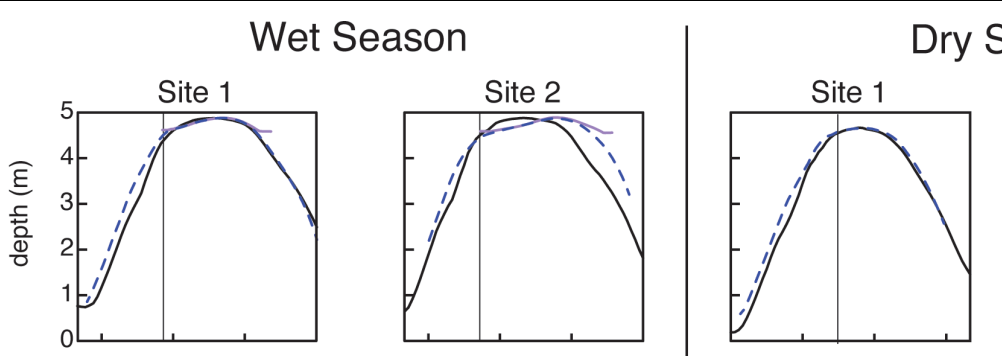

ry Season
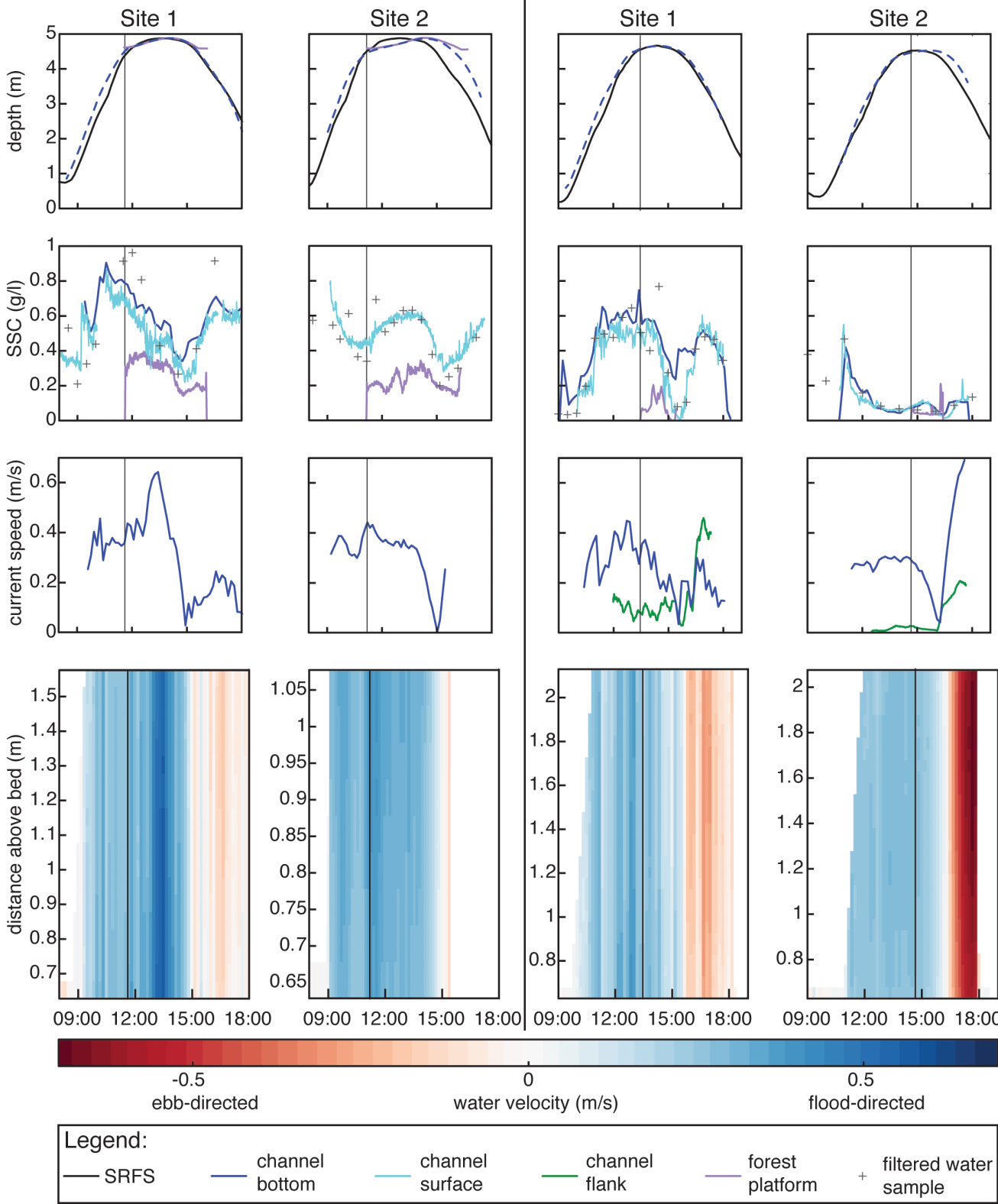

FIGURE 3 | Observations from the single-day experiments, including depth (relative to SRFS), SSC, and water velocity within the tidal channel. In general, we observe a decrease in both flood-oriented current velocity and SSC within the tidal channel from Site 1 to Site 2 (exterior to interior of the sub-basin), and from wet season to dry season. Vertical black line corresponds to the timing of platform inundation, as measured by the platform OBS.

the dry season, the same locations exhibited mean SSC of 0.32 and $0.10 \mathrm{~g} / \mathrm{l}$, representing reductions of 38 and $80 \%$ (Table $\mathbf{1}$ and Figure 3). SSC maxima at the channel surface were greatest during the wet season, although the relative decrease during the dry season was not as drastic as for the mean. Max SSC during the wet season were $0.86 \mathrm{~g} / \mathrm{l}$ (Site 1) and $0.79 \mathrm{~g} / \mathrm{l}$ (Site 2), compared to dry season SSC of 0.64 and $0.55 \mathrm{~g} / \mathrm{l}$ at the same locations, for respective reductions of 26 and 30\% (Table 1 and Figure 3). In each case, the decrease in SSC within the SNF is smaller than at the longer-term observation station SRFS, where SSC maxima during the wet season field work were $\sim 0.8 \mathrm{~g} / \mathrm{l}$, vs. $\sim 0.4 \mathrm{~g} / \mathrm{l}$ dry season (Figure 1).

\section{Sediment Grain Size}

Median grain size on the platform decreases from $31 \mu \mathrm{m}$ at the confluence with the Sutarkhali River to $15 \mu \mathrm{m}$ near Site 2 (Figure 4). Within the channel, samples collected near Site 1 exhibit median diameters ranging from 13 to $30 \mu \mathrm{m}$, while samples near Site 2 are uniformly finer grained $(\sim 19 \mu \mathrm{m})$. Interestingly, there is no obvious difference between samples 


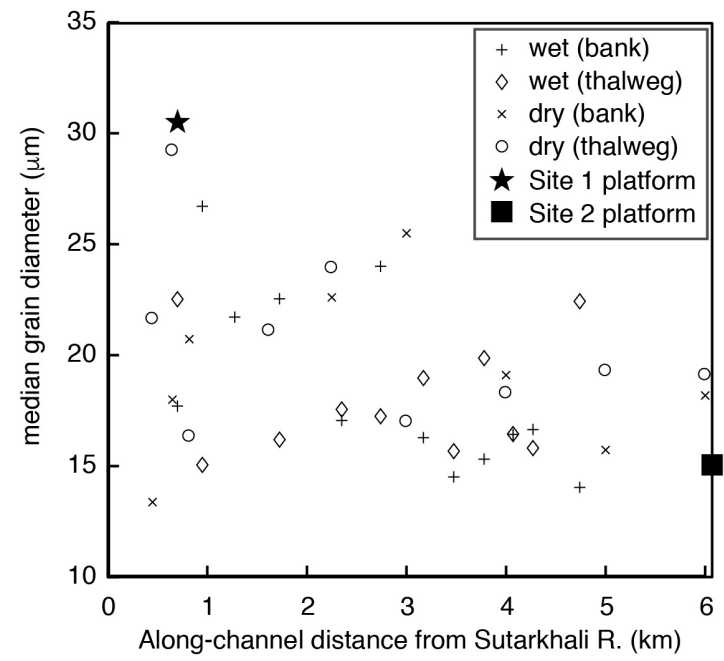

FIGURE 4 | Median grain diameter within the sub-basin plotted against distance from the Sutarkhali River, the conduit for both sediment and water. There is no obvious trend according to season or sample elevation within the channel, although there is a weak trend of decreasing grain size with distance inland.

collected in the thalweg vs. the channel flank, nor is there a discernible change between seasons (Figure 4).

\section{DISCUSSION}

The field instrument deployment strategy used in this study is admittedly limited in both temporal and spatial coverage due to access issues, safety concerns, and available resources. That said, we are able to provide measurements of sediment in the tidal channels at two locations within this sub-basin, paired with observations on the mangrove platform 50-90 m inland (Figure 1). In doing so, we can address sedimentation conditions in the best-case scenario (wet season at Site 1), and a substantially less-optimal example (dry season at Site 2). Finally, extrapolating from a handful of tidal cycles to a year's worth of deposition will never capture the full range of sedimentary or diagenetic processes, even if our measurements occur during periods corresponding to the annual minima and maxima for conditions related to sedimentation (Figure 2). Instead, as we demonstrate in the following sections, we are encouraged that based on the similarity of our extrapolated deposition rates, and those observed by previous and concurrent studies (Rogers et al., 2013; Bomer et al., in review), we appear to be measuring and comparing the appropriate controlling forces. Future research in this area should build upon these initial observations to develop numerical simulations (sensu Horstman et al., 2015) that will help explain both spatial and temporal variability that this study can not address.

\section{Sedimentation Controls}

A persistent challenge in untangling the controls on sedimentation is that they are often covariant. This is clearly the case on the platform in the SNF, as the dry season features lessfrequent and shallower inundation depths, shorter inundation durations, and lower SSC (Table 1 and Figure 3), all of which likely combine to reduce seasonal deposition. One parameter that remains consistent across seasons is the grain size distribution, which controls settling velocity and therefore the efficiency of sediment delivery to and across the platform (Figure 4). Our laboratory analysis of particle sizes, however, ignores the potential for sediment aggregation as a result of either biological processes or the electrochemical properties of fine-grained particles in salt water (e.g., Mietta et al., 2009; Manning et al., 2013). Aggregates (loosely cohesive packets of fine-grained sediment and organic matter) can behave like coarser particles in the water column, requiring additional turbulence to be advected upward, and settling more rapidly during periods of slack water (Manning et al., 2013). We might expect, therefore, that surface SSC in the dry-season channel is reduced more rapidly at slack water than during the wet-season. This effect can be observed most clearly in the time series observations of SSC at Site 1 during the wet and dry seasons (Figure 3). During the monsoon, there is relatively little difference between SSC at the channel surface and bottom, suggesting a well-mixed water column, and relatively little settling by what we assume to be disaggregated sediment particles. While the lowest values of SSC are observed near slack-high tide (Figure 3), there is generally poor correlation between velocity and SSC (Figure 5). During the dry season, on the other hand, not only is there a stronger coupling between SSC and velocity (Figure 5), but while near-bed SSC reduces by $\sim 60 \%$ to $\sim 0.2 \mathrm{~g} / \mathrm{l}$, surface SSC decreases to effectively $0 \mathrm{~g} / \mathrm{l}$ (Figure 3). Similarly, wet season SSC on the platform at Site 1 is $61 \%$ lower than SSC in the channel at the onset of inundation $(0.26 \mathrm{~g} / \mathrm{l}$ vs. $0.67 \mathrm{~g} / \mathrm{l}$; Figure 3). During the dry season, the reduction from channel to platform is closer to $90 \%$ (0.50 to $0.05 \mathrm{~g} / \mathrm{l}$; Figure 3). In each case, the implication is that not only is the overall sediment supply reduced during the dry season, but the sediment in suspension is actually largely unavailable to nourish platform interiors within vegetated sub-basins (here extending $\sim 6 \mathrm{~km}$ from the main Sutarkhali channel). This observation does not discount the presence of biological aggregation, however, we interpret the enhanced dry-season settling as indicative of the relatively greater importance of electrochemical processes here.

Based on our observations of environmental conditions, we expect substantially more sediment to be deposited on the platform during the wet season than the dry season. At a fundamental level, we observe that the platform floods more frequently and to greater depth because of the seasonal waterlevel setup ( $\sim 25 \mathrm{~cm}$; Figure 2$)$, and the water flooding the platform is carrying dramatically more sediment in suspension (0.22-0.27 vs. $0.05-0.08$ g/l; Table 1 and Figures 3, 5). These conditions should promote enhanced deposition, as described by Rogers et al. (2013). In their study of deposition rates at the same locations as this study, Bomer et al. (in review) also observe substantially more frequent and prolonged inundation during the wet season. Those authors measured an average vertical accretion of $1.44 \pm 0.35 \mathrm{~cm}$ during the wet season (typically measured in October), compared to $0.94 \pm 0.27 \mathrm{~cm}$ during 


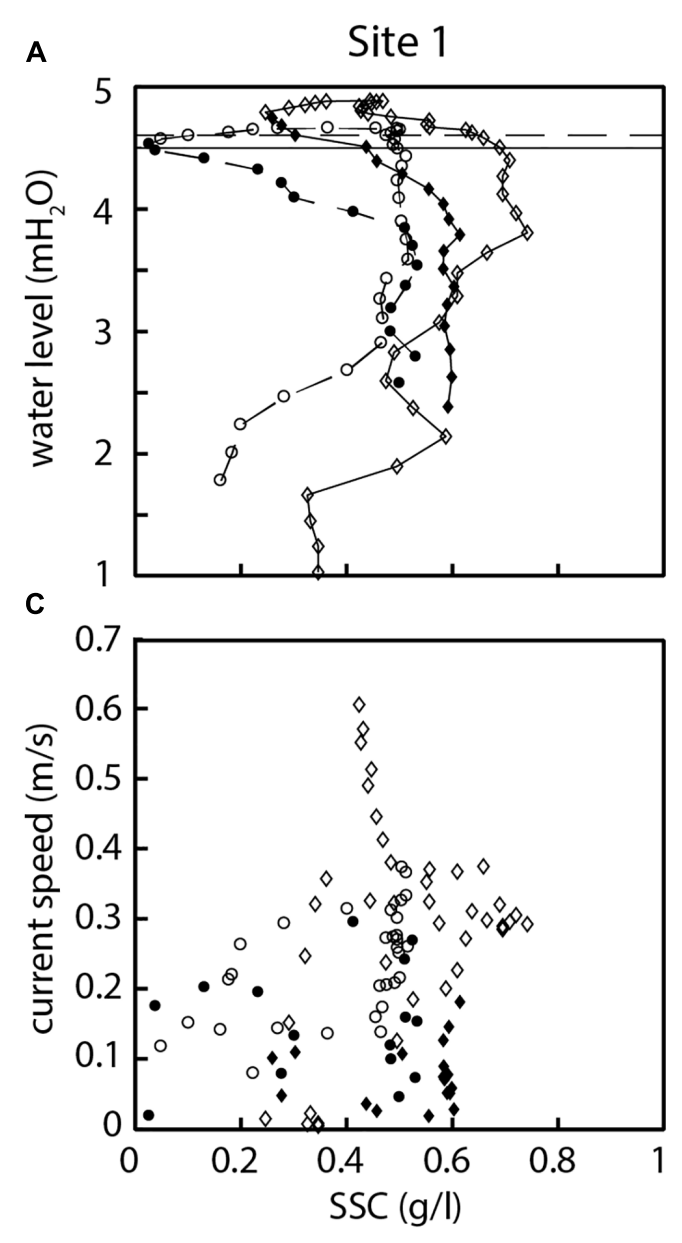

B

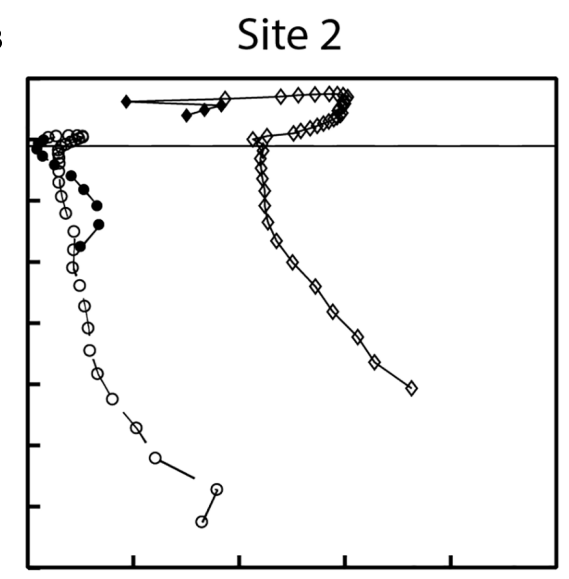

D

FIGURE 5 | Water level against tidal-channel SSC (A,B) and depth-averaged current speed against tidal-channel SSC (C,D), for Site 1 (left) and Site 2 (right). SSC maxima occur immediately prior to inundation at Site 1, and near water-level minima at Site 2. SSC is generally higher during flood currents (open symbols), however, current speed is a poor predictor of SSC in either season.

the dry season (typically measured in March-May), with no significant difference between the groups.

As described in the section "Materials and Methods," we estimate the amount of sediment deposited on each tidal cycle, assuming that the difference between the maximum flood-limb SSC and the minimum ebb-limb SSC is the product of deposition. This assumption is supported by a comparison of the settling velocities of the particles at each site, to the depth of the water column at each location. Based on Gibbs et al. (1971), we would expect the median grain size particles at Site $1(31 \mu \mathrm{m})$ and Site 2 $(14 \mu \mathrm{m})$ to settle at rates of 0.085 and $0.023 \mathrm{~cm} / \mathrm{s}$, respectively. These values are likely conservative, as mud particles often aggregate or flocculate as described above, settling at faster rates than the constituent particles (Mietta et al., 2009). Based on these conservative settling rates and the inundation depths described in Table 1, we would expect that during the wet season, the water column at Site 1 could be evacuated of sediment in as few as 7 min during slack high water, while site 2 might require as long as $30 \mathrm{~min}$ of placid conditions. According to our velocity measurements in the tidal channel - a much more dynamic environment - near-slack conditions $(\mathrm{U}<0.10 \mathrm{~m} / \mathrm{s}$ ) persist for $\sim 40 \mathrm{~min}$ at each location, offering ample time for sediment to settle from suspension (Figure 3). Previous research has demonstrated the effectiveness of pneumatophores at trapping sediment, with the mangrove platform often serving as a oneway pump for fine-grained material (Wolanski, 1995; Furukawa et al., 1997; Victor et al., 2004). As such, conditions promoting sediment accumulation are unlikely to improve with increased distance from the channel. Our observations should therefore be considered a "best-case" scenario. Locations further from the sediment source are unlikely to demonstrate deposition rates faster than those estimated here, given the well-understood process of reduced SSC with distance from source both from the literature (e.g., Delaune et al., 1978; Reed, 1988; Christiansen et al., 2000), and between Site 1 and Site 2 in this study (Figure 3).

To estimate deposition on the platform during a single tidal cycle, we can begin with an examination of the observations made at Site 1 during the wet season, where we observe a maximum SSC of $0.39 \mathrm{~g} / \mathrm{l}$ during the flood limb, and a minimum SSC of $0.14 \mathrm{~g} / \mathrm{l}$ on the ebb. Interestingly, this reduction in SSC 
$(0.25 \mathrm{~g} / \mathrm{l})$ is almost identical to the difference back-calculated by Auerbach et al. (2015), when considering sediment deposition in the adjacent poldered region. Assuming that the SSC we measured near the platform bed was consistent throughout the $\sim 0.39 \mathrm{~m}$ water column, $97.5 \mathrm{~g} / \mathrm{m}^{2}$ of sediment would come out of suspension at slack high water. Dry bulk density for surface samples collected at Site 1 is $1100 \mathrm{~kg} / \mathrm{m}^{3}$ in the wet season, and the resulting quotient suggests deposition of $8.7 \times 10^{-3} \mathrm{~cm}$ per inundation cycle (Table 1). While this value may appear unimpressive, the significance is gained when we extrapolate based on the number of inundation periods that occur under similar conditions of SSC and depth. If we assume, for example, that this location is influenced by similar peak monsoon forces for 90 days (180 inundation periods) per year, we would expect deposition of $\sim 1.6 \mathrm{~cm}$ during that time frame (Table 1); similar to the average deposition of $1.1 \mathrm{~cm} /$ wet season observed by Rogers et al. (2013). The same location we would expect an order of magnitude lower deposition $(0.3 \mathrm{~cm})$ based on the conditions observed during the dry season (Table 1). Predicted deposition rates at Site 2 are similar to Site 1, ranging from 2.1 to $0.06 \mathrm{~cm} /$ season for the wet and dry seasons, respectively (Table 1). Of course, these estimates assume that the entire decrease in SSC at slack high tide is a result of deposition, that there is no subsequent erosion, and that this accounts for all of the deposition that occurs during a given inundation cycle. These assumptions are justified based on our calculations of settling times $(<10 \mathrm{~min})$, our observations of little to no sediment resuspension on the platform (Figure 3), and the observations of Furukawa et al. (1997) who describe sediment trapping by pneumatophores. We concede here, however, that these backof-the-envelope calculations only apply directly to the interior of the vegetated platform proximal to $(50-90 \mathrm{~m})$ the channel margin, as it is readily accepted that sediment accumulation decreases - often exponentially - with distance from the channel edge (Delaune et al., 1978; Reed, 1988; Christiansen et al., 2000). For the wet season, at least, our average predicted deposition (1.8 cm; Table 2) compares favorably with the measurements made by Bomer et al. (in review; $1.4 \mathrm{~cm}$; Table 2). Our dry-season prediction $(0.3 \mathrm{~cm})$ on the other hand, is much lower than was observed by Bomer et al. (in review; $0.9 \mathrm{~cm}$; Table 2). Again, our observations are from individual days extrapolated across an entire season, so a one-for-one comparison is likely not reasonable. Furthermore, Bomer et al.'s (in review) measurements of seasonal sediment deposition were typically made in September-October (wet season) and MarchMay (dry season); periods of time that were sensibly based on the Ganges-Brahmaputra river discharge. As we can see in this study, however, monsoon-like conditions (nearly fresh water, elevated SSC, higher water levels) persist in the tidal channels well into November (Figure 2), allowing for the potential of additional deposition that would be attributed to the dry season in that study. Additionally, in this analysis we are assuming that conditions remain similar throughout either the monsoon or dry season, which we know to be a simplification (Figure 2). We are nevertheless encouraged by the similarities between our calculation and measurements from previous research, and look
TABLE 2 | Predicted change in seasonal deposition according to the projected changes in suspended sediment supply and fresh water due to the IRLP, as described by Higgins et al. (2018).

\begin{tabular}{lcc}
\hline & $\begin{array}{c}\text { Wet Season } \\
\text { Average (cm) }\end{array}$ & $\begin{array}{c}\text { Dry Season } \\
\text { Average (cm) }\end{array}$ \\
\hline $\begin{array}{l}\text { Measured vertical accretion (Bomer } \\
\text { et al., in review) }\end{array}$ & 1.4 & 0.9 \\
Predicted deposition (this study) & 1.8 & 0.2 \\
$14 \%$ reduction in sediment supply & 1.6 & $<0.2$ \\
$18 \%$ reduction in sediment supply & 1.4 & $<0.1$ \\
$18 \%$ reduction in & 1.0 & $<0.1$ \\
sediment +1 month shorter & & \\
freshwater conditions & & \\
\hline
\end{tabular}

forward to future colleagues extending these results with a fullscale numerical simulation, the likes of which was outside the scope of the present research.

\section{Comparison Between Locations}

In addition to the profound seasonal changes observed at our study locations, there are also important distinctions from within our sub-basin that help us better understand how sediment dynamics evolve within Ganges Brahmaputra tidal sub-basins as a whole. One factor is platform elevation, which is not only different between Sites 1 and 2, but the magnitude of this difference appears to change across seasons. To assess this variability, we adjust the inundation depth by the difference in the absolute magnitude of tide height as measured at SFRS (Figure 5). During the wet season, the platform elevation at Site 2 is approximately $4 \mathrm{~cm}$ lower than Site 1. During the dry season, this difference extends to $15 \mathrm{~cm}$ (Figure 5). This calculation relies on the assumptions that the instrument deployment locations are identical across seasons, as is the modification of the tidal waveform between SRFS and the study sites. Given the similarities between the relative inundation depths at each site across seasons, we consider these assumptions to be valid. We suggest that sediment texture plays an important role in controlling platform elevation. In short, the finer grains present at Site 2 (15 vs. $30 \mu \mathrm{m}$; Figure 4) are more susceptible to compaction from dewatering, which would be particularly important during the dry season when inundation frequency and duration are reduced (e.g., Knott et al., 1987; Nuttle and Hemand, 1988; Nuttle et al., 1990; Bomer et al., in review). This is further supported based on our observations of sediment dry bulk density at the platform surface, which is $~ 35 \%$ greater at Site 1 than Site 2 (means of 935 and $685 \mathrm{~kg} / \mathrm{m}^{3}$, respectively, Table 1), and which also increases by $\sim 10 \%$ from the wet to dry seasons at Site 2 (876 and $968 \mathrm{~kg} / \mathrm{m}^{3}$, respectively), suggesting that compaction is taking place.

Another factor driving the sediment dynamics is proximity to large conduit channels, particularly during the dry season when SSC delta-wide are lower (Barua, 1990; Hale et al., 2019). As described above, we observe relatively little difference between the in-channel SSC at Sites 1 and 2 during the wet season (Figure 3). In contrast, there is a dramatic difference between the two sites during the dry season, with substantially less SSC 
at the interior location (Site 2). The reason for this may be similar to the difference in the observed reduction of SSC from channel to platform described in section "Sedimentation Controls" above, where an overall decrease in material availability, and increased settling velocities due to salinity-induced flocculation combine to reduce the travel distance for a given particle. While this may seem relatively intuitive, this provides the first empirical evidence for this phenomenon within the SNF. This has very important implications as tidal river management (TRM) projects are being implemented in the poldered region with the goal of combating some of the deleterious side effects of the embankments. With TRM, periodic breaches of the polder wall reconnect sub-basin land with the tidal channel to accelerate land accretion (Khadim et al., 2013; Hossain et al., 2015). Based on our observations, TRM effectiveness would change dramatically based not only on the season, but also the distance from the larger tidal channels. We expect this concept to be explored in greater detail in the near future.

Beyond the obvious elevation difference observed in the sub-basin between Sites 1 and 2, and their relative distances from the Sutarkhali channel, they also exhibit fundamentally different behavior between channel hydrodynamics and sediment transport. In neither location is velocity a strong predictor of SSC (Figure 5). Indeed, the strongest correlation occurs at Site 2 during the dry season, where velocity explains $\sim 35 \%$ of the in-channel SSC variance. This weak relationship might suggest that at each site, local resuspension plays a less important role in controlling in-channel SSC than advection from up- or down-stream sources. While this may be true, the roles of local resuspension and advection are likely much more nuanced.

A comparison of the Shields parameter $\left(\theta_{t}\right)$ and roughness Reynolds number $\left(\operatorname{Re}_{*}\right)$ reveals that with the exception of slack high water, the critical shear stress for resuspension is always exceeded (Table 1; Shields, 1936; Miller et al., 1977). Here, shear velocity was determined calculated as the quotient of von Kármán's constant divided by the slope of the curve of velocity versus the natural log of depth, as described by the Law of the Wall. We performed these calculations using data from the relatively quiescent dry season; the stronger velocities observed during the wet season would only serve to enhance shear in the water column and stress on the bed. Of course, evaluating the Shields parameter in fine-grained systems can be fraught, however, our primary reason for using it here is to highlight an interesting difference in the timing of SSC maxima observed at our two field locations. At Site 1, the maximum flood-limb SSC occurs immediately prior to platform inundation during both the wet and dry season (Figure 5). This region is characterized by broad ( $\sim 15 \mathrm{~m}$-wide), muddy banks, which can continuously provide sediment for resuspension as they inundate, assuming sufficiently strong shear velocities. In contrast, peak flood-limb SSC at Site 2 is observed near the lowest water levels, long before any material in suspension could be delivered to the platform. The channel has narrowed substantially at this distance inland, and is completely drained during spring low tides during the wet and dry seasons. The banks here are not as wide as at Site 1 and are heavily vegetated, which can baffle near-bed flow as the water elevation rises, thereby preventing additional erosion (Furukawa and Wolanski, 1996). Figure 3 compares the average current speed from the upward-looking ADCP (located on the channel bottom), with the velocity on the channel flank, $\sim 1.25 \mathrm{~m}$ below the platform elevation, during the dry season. While the flood velocities in the channel were similar at the two locations, the velocities on the bank were dramatically different. At Site 2, the maximum flooding velocity on the bank was $0.03 \mathrm{~m} / \mathrm{s}$, a full order of magnitude lower than the fastest channel velocity, and unlikely to resuspend bank sediment. In contrast, Site 1 demonstrated bank velocities as fast as $0.15 \mathrm{~m} / \mathrm{s}$, which is $34 \%$ as fast as the channel velocity, and certainly capable of resuspension (Figure 3). This additional source of sediment is one of several mechanisms that help to explain the increased deposition seen at Site 1 relative to Site 2 , as observed by Bomer et al. (in review; Table 1).

\section{Spatio-Temporal Variability and Future Implications}

Interestingly, the deposition rates determined by this and other recent studies (e.g., Rogers et al., 2013; Auerbach et al., 2015; Bomer et al., in review) are similar to the local deposition rates observed across the entire Holocene $(0.7-1.0 \mathrm{~cm} /$ year; Ayers et al., 2016). Further to the west, where sedimentation has been reduced as a result of the eastward migration of the Ganges River over the past 4000 years, the longterm deposition rates are closer to $0.1-0.2 \mathrm{~cm} /$ year (Flood et al., 2015). It would be an oversimplification to imply that this spatial variability stems exclusively from a moving sediment supply. Many boundary conditions, including upstream sediment supply, reservoir construction, sea level, and polder construction have all played a role in effecting delta-wide sedimentation. Nevertheless, the area that has been subject to the most-dramatic decrease in sediment supply (western delta plain) also demonstrates a reduced accumulation rate. This provides important context for the effects of a reduced sediment supply to the SNF- which we can augment with our observed differences between wet season and dry season SSC and sedimentation.

For example, consider the possible impacts of a reduced sediment discharge associated with India's planned dams and diversions through the NRLP on sedimentation in the SNF: if fully implemented, one result would be a reduction in the annual suspended sediment load of the Ganges and Brahmaputra rivers by $39-75 \%$ and $9-25 \%$, respectively, with the majority of this reduction occurring during the wet season (Higgins et al., 2018). Collectively, this amounts to a reduction in the total suspended sediment load by $14-18 \%$. Rogers et al. (2013) estimate that approximately two thirds of the sediment deposited each monsoon season is of recent (<6 month) Ganges-Brahmaputra origin, with the remainder being sourced from antecedent shelf and floodplain deposits. Using the more optimistic estimate of sediment load reduction (14\%), average wet-season deposition is reduced from 1.8 to $\sim 1.6 \mathrm{~cm}$ (Table 2). Using instead the high-end estimate for total sediment 
load reduction, wet-season deposition decreases further to $\sim 1.4 \mathrm{~cm}$ (Table 2). In both scenarios, dry season deposition is $<0.2 \mathrm{~cm}$ (Table 2). Of course, by reducing the freshwater discharge of these rivers by 24 and $6 \%$ respectively, we can also expect the effective duration of monsoon-like conditions to be reduced by a month or more (Higgins et al., 2018). Indeed, if we rework our initial estimate of deposition to reflect a substantially shorter monsoon season (i.e., from 3 to 2 months, or 180 platform-inundating events to 120), wetseason deposition drops to $1.2 \mathrm{~cm}$. With less sediment being delivered to the region, a smaller freshwater contribution to the wet season water levels, and a longer duration of conditions that do not favor sedimentation, we expect sedimentation rates within the SNF to be reduced as a result of a fully implemented IRLP. Further, we expect the combined effects of these impacts to result in a greater reduction in sedimentation than any factor acting in isolation. Using the combined worstcase scenario of maximum suspended load reduction and a shortened wet season, our estimate of deposition drops to $<1 \mathrm{~cm}$ (Table 2). Without adequate sedimentation to offset the regional relative and effective rates of SLR, the SNF may drown in place as predicted by Loucks et al. (2010). Importantly, our analysis neglects the possibility of sediment supplied by channel scouring downstream of the dams associated with the IRLP, similar to the scenario on the Mississippi River described by Nittrouer and Viparelli (2014). That said, as we discussed in the previous sections, the majority of the platform is being supplied with silt and finer-grained sediment, as coarser grains are incapable of being transported to the platform interior. As such, this remains an important area of future research.

\section{CONCLUSION}

Sedimentation in the SNF is controlled by a combination of independent factors, including maximum water depth, sediment particle size, inundation duration, and SSC. Understanding the interaction of each of these parameters, as well as their relative importance, is critical to understanding the health and sustainability of the SNF and tidal deltaplain as a whole. Furthermore, the SNF stands out as a natural case study to contrast with the adjacent, heavily modified poldered region, where significant change is necessary to ensure continued habitability. In this study, we observe two overarching trends from a tidal sub-basin located in the SNF. First, we see that environmental conditions during the wet season are substantially more conducive to sediment deposition, with morefrequent and deeper inundation of the platform by fresh water enriched with suspended sediment. The apparent importance of salinity on controlling the formation of aggregates was a particularly interesting find with delta-wide implications in the face of future changes to the fresh water supply. Second, we see that the location proximal to the larger tidal channel (Site 1) exhibits greater SSC values, coarser grain size, and sits at a higher elevation than the location deeper in the forest (Site 2), regardless of season. Despite this, predicted monsoon deposition is actually greater at Site 2 than Site 1, largely because of the lower sediment bulk density (Table 1). This combination is particularly interesting, as it suggests that the coarser grains at Site 1 are building a more-stable platform capable of maintaining a higher elevation along the perimeter of SNF sub-basins, while the finer-grained interior is subject to more-intense compaction and dewatering. We must be cautious, therefore, in extrapolating our measurements from channel margins to span the entire lower delta, as the inaccessible interior regions may be more vulnerable to changes in sediment supply. We should also consider these results in practical applications like TRM, and ensure that sites selected for sluice gates have a sediment supply that is both robust and sufficiently coarse to build lasting platforms. Perhaps more important than the observations of the modern conditions are the implications of these observations in the context of scenarios for reduced sediment supply in response to upstream river damming and diversions. In the worst case, where sediment delivery is reduced by $14-18 \%$, and the duration of fresh water conditions is shortened by one month or more, we predict deposition rates $\sim 50 \%$ lower than are currently observed. Not only will this diminish the effectiveness of land reclamation strategies such as TRM, these rates are below those of local effective sea level rise, resulting in a threat to the continued viability of the SNF. Elevated SSC and fresh water conditions not only appear critical to the delivery of sediment from the tidal channels to the mangrove platform, but are also most likely to be affected by changes to the fresh water or sediment discharges of the larger Ganges and Brahmaputra rivers.

\section{AUTHOR CONTRIBUTIONS}

$\mathrm{RH}$ was responsible for study design and acquiring funding. $\mathrm{RH}$, $\mathrm{CW}$, and EB conducted the field work. $\mathrm{RH}$ drafted the initial report, which was subsequently revised by all authors, each of who contributed to the intellectual content.

\section{FUNDING}

This work was supported by the National Science Foundation (Coastal SEES- \#1600319) and CRDF Global (OISE-17-63730-0).

\section{ACKNOWLEDGMENTS}

The local access was granted by Abu Naser Hossain of the Forestry Crime Department, and accommodations arranged by Nasrul Islam Bachchu of Pugmark Tours. The authors extend their deepest gratitude to the captains and crew of the M/V Bawali, M/L Mawali, and M/L Sundari Trawler for their patience and support. We would like to thank Md. Saddam Hossain, Abdullah Al Nahian, and Sourov Bijoy Datta for logistics and field support and Dr. Steven Goodbred, two reviewers, and the editor for their comments that substantially improved the manuscript. 


\section{REFERENCES}

Allen, J. R. L. (1990). Salt-marsh growth and stratification: a numerical model with special reference to the Severn Estuary, Southwest Britain. Mar. Geol. 95, 77-96. doi: 10.1016/0025-3227(90)90042-i

Allison, M., and Kepple, E. (2001). Modern sediment supply to the lower delta plain of the Ganges-Brahmaputra River in Bangladesh. Geo Mar. Lett. 21, 66-74.

Alongi, D. M. (2012). Carbon sequestration in mangrove forests. Carbon Manag. 3, 313-322. doi: 10.4155/cmt.12.20

Auerbach, L. W., Goodbred, S. L. Jr., Mondal, D. R., Wilson, C. A., Ahmed, K. R., Roy, K., et al. (2015). Flood risk of natural and embanked landscapes on the Ganges-Brahmaputra tidal delta plain. Nat. Clim. Change 5, 153-157. doi: $10.1038 /$ nclimate 2472

Ayers, J. C., George, G., Fry, D., Benneyworth, L., Wilson, C., Auerbach, L., et al. (2017). Salinization and arsenic contamination of surface water in southwest Bangladesh. Geochem. Trans. 18:4. doi: 10.1186/s12932-017-0042-3

Ayers, J. C., Goodbred, S. L., George, G., Fry, D., Benneyworth, L., Hornberger, G., et al. (2016). Sources of salinity and arsenic in groundwater in southwest Bangladesh. Geochem. Trans. 17:4. doi: 10.1186/s12932-016-0036-6

Badola, R., and Hussain, S. A. (2005). Valuing ecosystem functions: an empirical study on the storm protection function of Bhitarkanika mangrove ecosystem, India. Environ. Conserv. 32, 85-92. doi: 10.1017/s037689290500 1967

Barua, D. K. (1990). Suspended sediment movement in the estuary of the GangesBrahmaputra-Meghna river system. Mar. Geol. 91, 243-253. doi: 10.1016/00253227(90)90039-m

Barua, D. K., Kuehl, S. A., Miller, R. L., and Moore, W. S. (1994). Suspended sediment distribution and residual transport in the coastal ocean off the Ganges-Brahmaputra river mouth. Mar. Geol. 120, 41-61. doi: 10.1016/00253227(94)90076-0

Capo, S., Sottolichio, A., Brenon, I., Castaing, P., and Ferry, L. (2006). Morphology, hydrography, and sediment dynamics in a mangrove estuary: the Konkoure Estuary, Guinea. Mar. Geol. 230, 199-215.

Carlton, J. M. (1974). Land-building and stabilization by mangroves. Environ. Conserv. 1, 285-294. doi: 10.1017/s0376892900004926

Christiansen, T., Wiberg, P. L., and Milligan, T. G. (2000). Flow and sediment transport on a tidal salt marsh surface. Estuar. Coast. Shelf Sci. 50, 315-331. doi: $10.1006 /$ ecss. 2000.0548

Delaune, R. D., Patrick, W. H., and Buresh, R. J. (1978). Sedimentation rates determined by $137 \mathrm{Cs}$ dating in a rapidly accreting salt marsh. Nature 275 , 532-533. doi: 10.1038/275532a0

Flood, R. P., Barr, I. D., Welte, G. J., Roberson, S., Russel, M. I., Meneely, J., et al. (2018). Provenance and depositinal variability of the Thin Mud Facies in the lower Ganges-Brahmaputra delta, West Bengal Sundarbans, India. Mar. Geol. 395, 198-218. doi: 10.1016/j.margeo.2017.09.001

Flood, R. P., Orford, J. D., McKinley, J. M., and Roberson, S. (2015). Effective grain size distribution analysis for interpretation of tidal-deltaic facies: West Bengal Sundarbans. Sediment. Geol. 318, 58-74. doi: 10.1016/j.sedgeo.2014.12.007

French, J. R. (1993). Numerical simulation of vertical marsh growth and adjustment to accelerated sea-level rise, north Norfolk, UK. Earth Surf. Process. Landf. 18, 63-81. doi: 10.1002/esp.3290180105

Furukawa, K., and Wolanski, E. (1996). Sedimentation in mangrove forests. Mangroves and Salt Marshes 1, 3-10. doi: 10.1023/A:1025973426404

Furukawa, K., Wolanski, E., and Mueller, H. (1997). Currents and sediment transport in mangrove forests. Estuar. Coast. Shelf Sci. 44, 301-310. doi: 10. 1006/ecss.1996.0120

Ghosh, M. K., Kumar, L., and Roy, C. (2016). Mapping long-term changes in mangrove species composition and distribution in the sundarbans. Forests 7:305. doi: 10.3390/f7120305

Gibbs, R. J., Matthews, M. D., and Link, D. A. (1971). The relationship between sphere size and settling velocity. J. Sediment. Res. 41, 7-18.

Google Earth (2015). Google Earth V 7.1.8.3036. Southern Bangladesh. TerraMetrics 2019. (accessed February 2, 2018).

Google Earth (2017). Google Earth V 7.1.8.3036. Southern Bangladesh. Digital Globe 2019. (accessed February 2, 2018).

Hale, R. P., Bain, R., Goodbred, S. Jr., and Best, J. (2019). Observations and scaling of tidal mass transport across the lower Ganges-Bramaputra delta plain: implications for delta management and sustainability. Earth Surf. Dynam. 7, 231-245, doi: 10.5194/esurf-7-231-2019

Higgins, S., Overeem, I., Rogers, K., and Kalina, E. (2018). River linking in India: downstream impacts on water discharge and suspended sediment transport to deltas. Elem. Sci. Anth. 6:20. doi: 10.1525/elementa.269

Horstman, E. M., Dohmen-Janssen, C. M., Bouma, T. J., and Hulscher, S. J. M. H. (2015). Tidal-scale flow routing and sedimentation in mangrove forests: combining field data and numerical modelling. Geomorphology 228, 244-262. doi: 10.1016/j.geomorph.2014.08.011

Hossain, F., Khan, Z. H., and Shum, C. K. (2015). Tidal river management in Bangladesh. Nat. Clim. Change 5:492. doi: 10.1038/nclimate2618

Khadim, F. K., Kar, K. K., Halder, P. K., Rahman, M. A., and Morshed, A. M. (2013). Integrated water resources management (IWRM) impacts in south west coastal zone of Bangladesh and fact-finding on tidal river management (TRM). J. Water Resour. Protect. 5:953. doi: 10.4236/jwarp.2013.510098

Knott, J. F., Nuttle, W. K., and Hemond, H. F. (1987). Hydrologic parameters of salt marsh peat. Hydrol. Process. 1, 211-220. doi: 10.13287/j.1001-9332.201704.033

Krone, R. B. (1987). “A method for simulating historic marsh elevations," in Coastal Sediments, ed. N. C. Krause (New York, NY: ASCE), 316-323.

Loucks, C., Barber-Meyer, S., Hossain, M. A. A., Barlow, A., and Chowdhury, R. M. (2010). Sea level rise and tigers: predicted impacts to Bangladesh's Sundarbans mangroves. Clim. Change 98, 291-298. doi: 10.1007/s10584-009-9761-5

Manning, A. J., Spearman, J. R., Whitehouse, R. J., Pidduck, E. L., Baugh, J. V., and Spencer, K. L. (2013). "Flocculation dynamics of mud: sand mixed suspensions," in Sediment Transport Processes and Their Modeling Applications, ed. A. J. Manning (London: InTechOpen).

Mcleod, E., Chmura, G. L., Bouillon, S., Salm, R., Björk, M., Duarte, C., et al. (2011). A blueprint for blue carbon: toward an imporved understanding of the role of vegetated coastal habitats in sequestering CO2. Front. Ecol. Environ. 9, 552-560. doi: 10.1890/110004

Mietta, F., Chassagne, C., Manning, A. J., and Winterwerp, J. C. (2009). Influence of shear rate, organic matter content, $\mathrm{pH}$ and salinity on mud flocculation. Ocean Dyn. 59, 751-763. doi: 10.1007/s10236-009-0231-4

Miller, M. C., McCave, I. N., and Komar, P. (1977). Threshold of sediment motion under unidirectional currents. Sedimentology 24, 507-527. doi: 10.1111/j.13653091.1977.tb00136.x

Nittrouer, J. A., and Viparelli, E. (2014). Sand as a stable and sustainable resource for nourishing the Mississippi River delta. Nat. Geosci. 7, 350-354. doi: 10.1038/ NGEO2142

Nuttle, W. K., and Hemand, H. F. (1988). Salt marsh hydrology: implications for biogeochemical fluxes to the atmosphere and estuaries. Glob. Biogeochem. Cycles 2, 91-114. doi: 10.1029/gb002i002p00091

Nuttle, W. K., Hemond, H. F., and Stolzenbach, K. D. (1990). Mechanisms of water storage in salt marsh sediments: the importance of dilation. Hydrol. Process. 4, 1-13. doi: 10.1002/hyp.3360040102

Pethick, J., and Orford, J. D. (2013). Rapid rise in effective sea-level in southwest Bangladesh: its causes and contemporary rates. Glob. Planet. Change 111, 237-245. doi: 10.1016/j.gloplacha.2013.09.019

Ray, R., Ganguly, D., Chowdhury, C., Dey, M., Das, S., Dutta, M. K., et al. (2011). Carbon sequestration and annual increase of carbon stock in a mangrove forest. Atmos. Environ. 45, 5016-5024. doi: 10.1016/j.atmosenv.2011.04.074

Reed, D. J. (1988). Sediment dynamics and deposition in a retreating coastal salt marsh. Estuar. Coast. Shelf Sci. 26, 67-79. doi: 10.1016/0272-7714(88)90012-1

Rogers, K. G., Goodbred, S. L. Jr., and Mondal, D. R. (2013). Monsoon sedimentation on the 'abandoned'tide-influenced Ganges-Brahmaputra delta plain. Estuar. Coast. Shelf Sci. 131, 297-309. doi: 10.1016/j.ecss.2013.07.014

Saenger, P., and Siddiqi, N. A. (1993). Land from the sea: the mangrove afforestation program of Bangladesh. Ocean Coast. Manag. 20, 23-39. doi: 10.1016/0964-5691(93)90011-m

Satyanarayana, B., Bhanderi, P., Debry, M., Maniatis, D., Foré, F., Badgie, D., et al. (2012). A socio-ecological assessment aiming at improved forest resource management and sustainable ecotourism development in the mangroves of Tanbi Wetland National Park, The Gambia, West Africa. Ambio 41, 513-526. doi: 10.1007/s13280-012-0248-7

Shaha, D. C., and Cho, Y. K. (2016). Salt plug formation caused by decreased river discharge in a multi-channel estuary. Sci. Rep. 6:27176. doi: 10.1038/srep27176

Shields, A. (1936). "Application of similarity principles nad turbulence research to bed-load movement," in Mitteilungen der Preussischen Versuchsanstalt fur 
Wasserbau und Schifbau, Berlin, eds W. P. Ott and J. C. van Uchelen (Pasadena, CA: California Institute of Technology).

Steckler, M. S., Nooner, S. L., Akhter, S. H., Chowdhury, S. K., Bettadpur, S., Seeber, L., et al. (2010). Modeling Earth deformation from monsoonal flooding in Bangladesh using hydrographic, GPS, and Gravity Recovery and Climate Experiment (GRACE) data. J. Geophys. Res. 115. doi: 10.1029/2009JB00 7018

Temmerman, S., Govers, G., Wartel, S., and Meire, P. (2004). Modelling estuarine variations in tidal marsh sedimentation: response to changing sea level and suspended sediment concentrations. Mar. Geol. 212, 1-19. doi: 10.1016/j. margeo.2004.10.021

Twilley, R. R., Rovai, A. S., and Riul, P. (2018). Coastal morphology explains global blue carbon distributions. Front. Ecol. Environ.. 16, 503-508. doi: 10.1002/fee. 1937

Victor, S., Golbuu, Y., and Wolanski, E. (2004). Fine sediment trapping in two mangrove-fringed estuaries exposed to contrasting land-use intensity, Palau, Micronesia. Wetlands Ecol. Manage 12, 277-283. doi: 10.1007/s11273-0058319-1
Wilson, C., Goodbred, S., Small, C., Gilligan, J., Sams, S., Mallick, B., et al. (2017). Widespread infilling of tidal channels and navigable waterways in humanmodified tidal deltaplain of southwest Bangladesh. Elem. Sci. Anth. 5:78. doi: 10.1525/elementa.263

Wolanski, E. (1995). “Transport of sediment in mangrove swamps," in Asia-Pacific Symposium on Mangrove Ecosystems. Developments in Hydrobiology, Vol. 106, eds Y. S. Wong and N. F. Y. Tam (Dordrecht: Springer).

Conflict of Interest Statement: The authors declare that the research was conducted in the absence of any commercial or financial relationships that could be construed as a potential conflict of interest.

Copyright $(\odot) 2019$ Hale, Wilson and Bomer. This is an open-access article distributed under the terms of the Creative Commons Attribution License (CC BY). The use, distribution or reproduction in other forums is permitted, provided the original author(s) and the copyright owner(s) are credited and that the original publication in this journal is cited, in accordance with accepted academic practice. No use, distribution or reproduction is permitted which does not comply with these terms. 